Financial Risk and Management Reviews

2021 Vol. 7, No. 1, pp. 50-59.

$\operatorname{ISSN}(e): 2411-6408$

$\operatorname{ISSN}(p): 2412-3404$

DOI: 10.18488/journal.89.2021.71.50.59

(C) 2021 Conscientia Beam. All Rights Reserved.

check for
updates

\title{
LIKELIHOOD OF INSURANCE COVERAGE ON DAMAGES DUE TO LEVEL OF INSECURITY IN NIGERIA: LOGISTIC MODELING APPROACH
}

(iD) Orumie Ukamaka
Cynthia $^{1}$
iD Desmond
Chekwube
Bartholomew $^{2+}$
iD Chukwudi Paul
Obite $^{3}$
iD Kiwu Chizoba
Lawrence $^{4}$

Article History

Received: 12 July 2021

Revised: 16 August 2021

Accepted: 3 September 2021

Published: 23 September 2021

\section{Keywords}

Insurance

Risk management

Binary logistic regression

Model

Likelihood test

Employment

Education.

JEL Classification: C10, C15.

\author{
'Department of Mathematics and Statistics, University of Port Harcourt, \\ Port Harcourt, Rivers State, Nigeria. \\ 'Email:amakaorumie@yahoo.com Tel: +2348064099683 \\ ${ }^{2,3,4}$ Department of Statistics, Federal University of Technology Owerri, \\ Owerri, Nigeria. \\ ${ }^{2}$ Email:desmond.bartholomew@futo.edu.ng Tel:+2347033811698 \\ ${ }^{s}$ Email: chukrudi.obite@futo.edu.ng Tel: +2347031143410 \\ "Email: lawrence.kiwen@futo.edu.ng Tel: +2348061580923
}

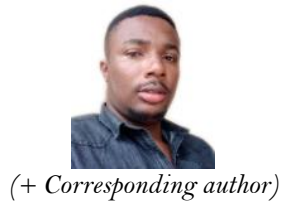

(+ Corresponding author)

\begin{abstract}
Insurance serves as a protection against the unexpected and it is one of the most effective risk management tools that protect individuals from being bankrupt due to various contingencies. The binary logistic regression model approach was used to model the described dataset; the model so obtained was statistically significant. All the levels of education were statistically significant in predicting the odds of having insurance cover except for primary education level. Also, employment status and age were statistically significant in predicting the likelihood for insurance cover in Nigeria. The results showed that individuals who move from no formal education to obtain Higher education level are 21.66 times more likely to obtain insurance cover and individuals who move from no formal education to obtain Secondary education level are 2.63 times more likely to obtain insurance cover. The odd ratio is not significant for moving from no formal education to Primary education and therefore should not be interpreted. Further, individuals who move from being unemployed to being employed are more likely to obtain insurance cover. Education has the highest impact in predicting the likelihood for one to have insurance cover in Nigeria. This paper recommends overhauling of the educational system in order to revamp this sector.
\end{abstract}

Contribution/Originality: The paper's primary contribution is finding that it assessed the impact of each level of the categorical predictor variables in predicting likelihood of insurance in Nigeria.

\section{INTRODUCTION}

It is usually impossible to avert an unexpected happening but one can have some protection against such unexpected occurrences. Insurance serves as a protection against the unexpected. Insurance is a legal agreement between two parties - the individual (insured) and the insurance company (insurer). The insurer promises to compensate for financial losses of the insured on happenings of the insured contingency. The insured is required to pay a premium usually monthly, quarterly or yearly in return for the promise made by the insurer. Insurance is one of the most effective risk management tools that protect individuals from being bankrupt due to various contingencies. Insurance is put in place to safeguard and protect citizens should certain unexpected evils happen. There are different types of insurance scheme and one can choose any of them as advised by financial experts. 
Financial experts will always advise that people should have all the insurance policies as it may be very difficult to determine the unexpected evil that will come and the exact insurance you need. There are five types of insurance recommended by most financial experts namely: life, health, long-term disability, automobile and home insurance.

The life insurance covers for one's funeral expenses and also to take care of those they left behind. The life insurance is very important if the person is the breadwinner of the family and has many people depending on him. The health insurance is also important because one serious illness can make a family to be bankrupt. A research of 900 Americans who presented personal bankruptcy case between 2013 to 2016, medical problem was the major reason for bankruptcy (Ramos et al., 2019). Many people think they may not need the long-term disability insurance, but the statistics from Social Security Administration showed that one-fourth of all workers will become disabled and will not be able to work before they get to their retirement age. This is different from health insurance; health insurance will take care of the medical bills but it would not take care of the daily expenses for the days when one is unable to work for weeks, months, or ever again. The automobile insurance covers for expenses for car accident and help guard against any litigation that might come up from the accident. Auto insurance also protects vehicles of the insured against vandalism, theft or a natural disaster. Home insurance covers for losses and damages caused to your home resulting from accidents like fire and other natural calamities. Insurance is necessary and important since it grants peace of mind to people. A business owner can take on certain business opportunities because they can shift the risk.

Some extant literature reveals that works have been done on insurance and some of these literatures are reviewed as follow: Nkengmenche (2020) studied different factors to ascertain how they affect the fast growth of life insurance in Cameroon. They discovered that poor integrity by the insurance companies, high cost of premiums, non-availability of the insurance companies in some part of the country, lack of disposable income, inefficiency in settling claims, and poor customers and distribution channels have a significant effect. In the fast growth of life insurance in Cameroon. The result of Nkengmenche (2020) is similar to what Salami (1996) discovered, that poor marketing relation and poor premium price has made many customers to allow their policies to lapse. Beck and Webb (2003) discovered that high income level per capital countries, countries with more developed banking sector, countries with low inflation rate, high private savings and real interest rate are more likely to purchase large amount of life insurance coverage. They also found out that education, life expectancy and dependency ratio of the young have no significant effect on the purchase of life insurance.

Buzatu (2013) studied the influence of behavioral factors on insurance decision using the Romanian Approach. He found out that different client approaches by the insurance companies, specific protection of clients based on the clients' behavioral issues, and financial awareness in the field significantly affect peoples' insurance decision. Park and Lemaire (2012) found out that countries with a large fraction of people with Islamic beliefs are less likely to buy an insurance policy. Hammond, Houston, and Melander (2007); Truett and Truett (2004) and Burnett and Palmer (2004) identified higher education as one of the factors that influences an individual in purchasing an insurance policy to protect their dependents. Yildirim and Cakar (2015) identified different factors that influences insurance companies' preference for insurance agencies operating in Turkey. Using information from a face-to-face interview from forty-nine agencies, they discovered that financial opportunities provided to agents, ability to pay the claims of policyholders by insurance companies, communication, and providing assistance are the major factors influencing insurance companies' preference of insurance agencies. A recent paper by Ugwuanyim, Onwuegbuchunam, Bartholomew, and Anikpe (2021) also found that claims settlement affects the volume of premiums received by insurance companies in Nigeria.

Insecurities have been a serious problem in Nigeria since the early 2000s. Armed militants were after oil industry infrastructure and kidnapping. Years later, it extended to farmer-herder conflicts, Islamic insurgents in Northern Nigeria, cultism, election violence, banditry involving Fulani herdsmen, etc. These insecurities have led to unexpected loss of properties and lives; and many health related issues (Ebiede, 2021). Those with an insurance 
cover always have some protection against such unexpected occurrences and can shift the risk to the insurer while those without any insurance cover suffer a lot and may become bankrupt due to the sudden financial burden the unexpected damages had caused. In this study, the researchers, seek to know the factors that influences peoples' choice of having an insurance cover in Nigeria, and to identify the relative risk of having an insurance based on some selected predictor variables.

Thus, the researchers want to solve the classification problem (insured or not insured) using binary logistic regression modeling based on some selected predictor variables in Nigeria by estimating the following: The relative risk in employment status for insurance cover in Nigeria with reference to employed individuals (as control level), the relative risk in education level for insurance cover in Nigeria with reference to no education individuals (as control level), the relative risk in individual age for insurance cover in Nigeria. Section 2 comprises the materials and method, whereas section 3 is the analysis, results output and interpretation. Sections 4 is the summary, conclusion and recommendation.

\section{MATERIALS AND METHOD}

This section discusses the statistical methodology used in this study.

\subsection{Binary Logistic Model}

Consider a model with three predictor variables (employment status, education level and respondent's age), $X_{1} X_{2}, X_{3}$, and one binary (Bernoulli) response variable $\mathrm{Y}$ (insurance cover) which we denote $\pi=\mathrm{P}(\mathrm{Y}=1)$. Linear relationship is assumed to exist between the predictor variables and the log-odds (also called logit) of the response. This linear relationship can be written in the following mathematical form as expressed in Equation 1 (where $\xi$ is the log-odds, $b$ is the base of the logarithm, and $\beta_{i}$ are parameters of the model):

$$
\xi=\log _{b} \frac{\pi}{1-\pi}=\beta_{0}+\sum_{i=1}^{3} \beta_{i} x_{i}
$$

exponentiating the log-odds gives the odds ratio or relative risk: in Equation 2

$$
\frac{\pi}{1-\pi}=b\left(\beta_{0}+\sum_{i=1}^{3} \beta_{i} x_{i}\right)
$$

By simple algebraic manipulation, dividing numerator and denominator by $b^{\left(\beta_{0}+\sum_{i=1} \beta_{i} x_{i}\right)}$, the probability that $Y=1$ is given in Equation 3

$$
\pi=\frac{b^{\left(\beta_{0}+\sum_{i=1}^{3} \beta_{i} x_{i}\right)}}{\left(b^{\left(\beta_{0}+\sum_{i=1}^{3} \beta_{i} x_{i}\right)}+1\right)}=\frac{1}{\left(b^{-\left(\beta_{0}+\sum_{i=1}^{3} \beta_{i} x_{i}\right)}\right)}=S_{b}\left(\beta_{0}+\sum_{i=1}^{3} \beta_{i} x_{i}\right)
$$


where $S_{b}$ is the sigmoid function with base $b$ (usually taken as $e$ ) are fixed.

The above formula shows that once $\beta_{i}$ are fixed, we can easily compute either the log-odds that $Y=1$ for a given observation, or the probability that $Y=1$.

This study is based on a dataset extracted from the 2018 Nigerian Demographic and Health Survey report. With a total of One Hundred and Twenty-Two Thousand Seven Hundred and Eighteen (122,718) respondents and no missing data. Since the outcome variable is binary count data with some categorical predictor variables, binary logistic model instead of ANOVA-type analysis is most suitable for modeling the outcome variable (Haeil, 2014). The data is described in Table 1 giving the first - ten rows because the data is too large.

Table-1. Data description.

\begin{tabular}{c|c|c|c|c}
\hline S/N & Education level & Employment status & age & Insurance cover \\
\hline 1 & 4 & 0 & 16 & 0 \\
\hline 2 & 4 & 0 & 17 & 1 \\
\hline 3 & 4 & 1 & 16 & 0 \\
\hline 4 & 4 & 0 & 16 & 0 \\
\hline 5 & 3 & 1 & 16 & 0 \\
\hline 6 & 4 & 1 & 17 & 0 \\
\hline 7 & 4 & 1 & 17 & 0 \\
\hline 8 & 4 & 1 & 17 & 0 \\
\hline 9 & 4 & 0 & 17 & 0 \\
\hline 10 & 4 & 0 & 18 & 0 \\
\hline
\end{tabular}

The first 10 rows of the dataset displayed in Table 1 was to enable description of the data used for the study. The response (outcome, dependent) variable called Insurance cover is binary in nature. There are three predictor variables: Education level, Employment Status and Respondent's age. Two of the predictor variables (Education level and Employment Status) are treated as categorical variables while Respondent's age as continuous. The variable Education level takes on the values 1 through 4 ( 1 =Higher education, $2=$ Secondary school, $3=$ Primary school and $4=$ No education) and Employment status takes on the values 0 through $1(1=$ Employed and $0=$ Not employed). The response variable takes on the values 0 through $1(1=$ Insured and $0=$ Not insured). The basic descriptive statistics of the data is displayed in Table 2.

\section{DATA ANALYSIS, RESULTS AND DISCUSSION}

The dataset is analyzed using $\mathrm{R}$ programming software, version 4.10 and the results are displayed in Tables and Figures below.

Table-2. Descriptive Statistics.

\begin{tabular}{c|c|c|c|c}
\hline & Education level & Employment status & age & Insurance cover \\
\hline Mean & & & 35.88115843 & \\
\hline Standard Error & & & 0.022618605 & \\
\hline Median & & & 36 & \\
\hline Mode & & & 35 & \\
\hline Standard Deviation & & & 7.92355258 & \\
\hline Sample Variance & & 1 & 62.78268548 & \\
\hline Maximum & 4 & 0 & 49 & 1 \\
\hline Minimum & 1 & 122718 & 15 & 0 \\
\hline Count & 122718 & & 122718 & 122718 \\
\hline IQR & & & 12 & \\
\hline
\end{tabular}




\subsection{Results and Discussion}

The minimum, median, mean and maximum age of the respondents were 15 years, 36 years, 36 years and 49 years as shown in Table 2. To further understand the nature of the dataset, cross tabulation of the categorical predictor variables with the response variable is displayed in Table 3.

Table-3. Cross tabulation.

\begin{tabular}{l|c|c|c|c|c|c|c}
\hline & \multicolumn{3}{|c|}{ Not Employed } & \multicolumn{3}{c|}{ Employed } & \\
\hline Education level & Not Insured & Insured & Total & Not Insured & Insured & Total & Grand Total \\
\hline Higher Education & 984 & 132 & 1,116 & 5,328 & 1,125 & 6,453 & 7,569 \\
\hline Secondary school & 4,854 & 210 & 5,064 & 22,736 & 633 & 23,369 & 28,433 \\
\hline Primary school & 3,899 & 76 & 3,975 & 19,768 & 144 & 19,912 & 23,887 \\
\hline No education & 22,082 & 211 & 22,293 & 40,183 & 353 & 40,536 & 62,829 \\
\hline Grand Total & 31,819 & 629 & 32,448 & 88,015 & 2,255 & 90,270 & 122,718 \\
\hline
\end{tabular}

From Table 3, out of the total 122,718 respondents whose responses were used for this study, 26\% (32,448) were unemployed while $74 \%$ (90,270) were employed. Out of the $26 \%$ that were unemployed, $98.1 \%(31,819)$ were also not insured and $1.9 \%$ (629) was insured. On the other hand, out of the $74 \%$ that were employed, 97.5\% (88,015) were not insured and $2.5 \%(2,255)$ were insured. This has reassured that employment status can explain some level of information about insurance cover in Nigeria since being employed increased the percentage insured by $0.6 \%$ $(2.5 \%-1.9 \%=0.6 \%)$. Again, out of the $2.5 \%(2,255)$ that were employed and insured, the percentage of people with higher education was $50 \%$, secondary school was $28 \%$, primary school was $6 \%$ while with no formal education was $16 \%$. This is an indication that education interacts with employment status to predict the likelihood of being insured in Nigeria. As a way of data screening to avoid misclassification, the boxplot was used to check the presence of outlier in the numerical predictor variable (age) and the output is shown in Figure 1. No presence of outlier in the variable since none of the data points fall outside the lower and upper whiskers.

\section{Box plot outlier detection in Age}

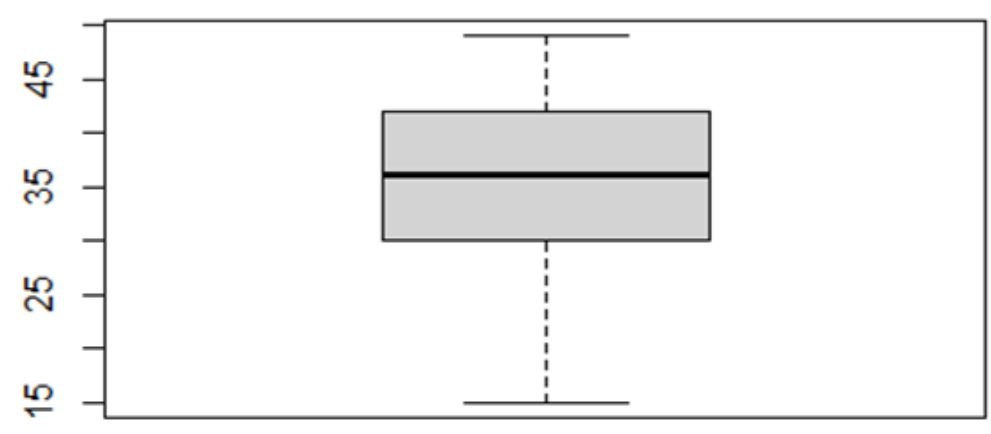

Figure-1. Outlier detection by box and whiskers plot.

Having visualized the dataset, we proceed with the logistic modeling using the variables as described. The output of the logistic model is displayed in Table 4.

The output in Table 4 as generated by using the $g \operatorname{lm}()$ function of the R console with family set as "binomial" to implement Equation 1 contains the regression coefficients, their standard errors, the z-statistic value and the corresponding p-values. Age, employment status and two levels of education level are statistically significant (their corresponding p-values are less than alpha 0.05). The logistic regression coefficients give the change in the log odds of the binary response for a one-unit increase in the predictor variable. 
Table-4. Logistic regression model output.

\begin{tabular}{|c|c|c|c|c|}
\hline \multicolumn{5}{|l|}{ Deviance Residuals: } \\
\hline Min & $1 Q$ & Median & $3 Q$ & Max \\
\hline-0.7309 & -0.2192 & -0.1413 & -0.1281 & 3.2060 \\
\hline Coefficients: & Estimate & Std. Error & $\mathrm{z}$ value & $\operatorname{Pr}(>|z|)$ \\
\hline (Intercept) & -5.55867 & 0.11265 & -49.346 & $<2 \mathrm{e}-16$ *** \\
\hline Education_level $^{1}$ & 3.12055 & 0.05358 & 58.237 & $<2 \mathrm{e}-16$ *** \\
\hline Education_level $^{2}$ & 1.28911 & 0.05601 & 23.015 & $<2 \mathrm{e}-16$ *** \\
\hline Education_level $^{3}$ & 0.03621 & 0.08049 & 0.450 & 0.653 \\
\hline employment_status ${ }^{0}$ & 0.21277 & 0.04898 & 4.344 & $1.40 \mathrm{e}-05 * * *$ \\
\hline age & 0.02126 & 0.00267 & 7.962 & $1.69 \mathrm{e}-15^{* * * *}$ \\
\hline \multicolumn{5}{|c|}{ 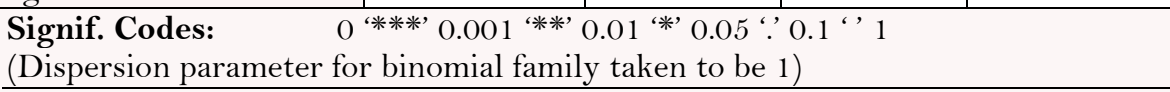 } \\
\hline \multicolumn{5}{|c|}{$\begin{array}{l}\text { Null deviance: } 27334 \text { on } 122,717 \text { degrees of freedom } \\
\text { Residual deviance: } 23267 \text { on } 122,712 \text { degrees of freedom } \\
\text { AIC: } 23279\end{array}$} \\
\hline Number of Fisher Sco & terations: 7 & & & \\
\hline
\end{tabular}

Thus, the following interpretations follow:

- For every one unit change in age, the log odds of insured (versus not insured) increases by 0.02.

The indicator variables for employment status and education level have slightly differently interpretation.

Since the reference levels for the two categorical variables are employed (1) and no education (4), we interpret as follow:

- Interviewing an unemployed individual versus interviewing an employed individual, changes the log odds of being insured by 0.213 .

- Interviewing an individual with higher education versus interviewing an individual with no education, changes the log odds of being insured by 3.121 .

- Interviewing an individual with secondary education versus interviewing an individual with no education, changes the log odds of being insured by 1.29 .

- Interviewing an individual with primary education versus interviewing an individual with no education, changes the log odds of being insured by 0.036. Though, this change is not statistically significant ( $p$-value 0.653 is greater than alpha 0.05 )

Below the table of coefficients in Table 4 are fit indices, including the null and deviance residuals and the AIC. The confidence intervals for the regression coefficients by using the confint() function is displayed in Table 5. The confidence intervals displayed are calculated using the profiled log-likelihood function.

Table-5. Confidence interval for the regression coefficients.

\begin{tabular}{l|c|c}
\hline & $\mathbf{2 . 5} \%$ & $\mathbf{9 7 . 5} \%$ \\
\hline (Intercept) & -5.78048289 & -5.33889321 \\
\hline Education_level $^{1}$ & 3.01609921 & 3.22618518 \\
\hline Education_level $^{2}$ & 1.17967364 & 1.39928610 \\
\hline Education_level $^{3}$ & -0.12337317 & 0.19233219 \\
\hline employment_status $^{0}$ & 0.11616508 & 0.30820585 \\
\hline age & 0.01603154 & 0.02649908 \\
\hline
\end{tabular}

We further test for an overall effect of employment status and education level (the categorical predictor variables) using the Wald Test() function of the aod library in R. The order in which the coefficients are given in the table of coefficients of Table 4 is used as the order of the terms in the model. Thus, The Wald test output is displayed in Table 6. 
Table-6. Wald Test for the significance of categorical predictor variables in the logit model.

\begin{tabular}{l}
\hline Wald test: \\
\hline Chi-squared test: \\
\hline $\mathrm{X} 2=4336.1, \mathrm{df}=3, \mathrm{P}(>\mathrm{X} 2)=0.000$. \\
\hline
\end{tabular}

The chi-squared test statistic of 4,336.1, with three degrees of freedom is associated with a p-value of 0.000 (less than alpha 0.05) indicating that the overall effect of the categorical predictor variables is statistically significant.

Further, we also tested additional hypotheses about the differences in the coefficients for the different levels of education level. To contrast these three terms (higher, secondary and primary education coefficients), we multiply one of them by 1 , and the other by -1 . The other terms in the model (employment status and age coefficients since they one term per variable) are not involved in the test, so they are multiplied by 0 . The result of this additional hypothesis is shown in Table 7 .

Table-7. Wald Test for significant difference in education level parameters.

\begin{tabular}{l}
\hline Wald test: \\
\hline Chi-squared test: \\
\hline $\mathrm{X} 2=398.8, \mathrm{df}=3, \mathrm{P}(>\mathrm{X} 2)=0.000$ \\
\hline
\end{tabular}

The chi-squared test statistic of 398.8 with 3 degree of freedom is associated with a p-value of 0.000 (less than alpha 0.05), indicating that the difference between the coefficient for education level $=1$, the coefficient for education level $=3$ and education level $=2$ is statistically significant.

In order to further understand the coefficients of the logit mode, the coefficients were exponentiated and the result interpreted as odds-ratios. To get the exponentiated coefficients, the exp () function was used. The odds ratios with their corresponding confidence intervals are displayed in Table 8.

Table-8. Odds ratio and 95\% confidence interval.

\begin{tabular}{|c|c|c|c|}
\hline & Odds Ratio & $2.5 \%$ & $97.5 \%$ \\
\hline (Intercept) & 0.003853907 & 0.003087224 & 0.004801182 \\
\hline Education_level ${ }^{1}$ & 22.658847100 & 20.411515243 & 25.183403384 \\
\hline Education_level $^{2}$ & 3.629564494 & 3.253312294 & 4.052305986 \\
\hline Education_level $^{3}$ & 1.036873981 & 0.883933745 & 1.212073089 \\
\hline employment_status ${ }^{0}$ & 1.237106448 & 1.123181268 & 1.360981112 \\
\hline age & 1.021487334 & 1.016160736 & 1.026853299 \\
\hline
\end{tabular}

Now the following interpretations follow:

- For a one unit increase in age, the odds of being insured (versus not being insured) increase by a factor of $1.021(1.021-1.000=0.021)$, that is about $2.1 \%$ increase in the likelihood to obtain an insurance cover.

- Moving from no education to higher education increases the odds of being insured by a factor of 22.66 (22.66 $-1.00=21.66)$, that is about $2166 \%$ increase in the likelihood to obtain an insurance cover.

- Moving from no education to secondary education increases the odds of being insured by a factor of 3.63 $(3.63-1.00=2.63)$, that is about $263 \%$ increase in the likelihood to obtain an insurance cover.

- Moving from no education to primary education has an impact which is not statistically significant. Thus, we do not report the odds ratio.

- Odds of being insured increases by $1.24(1.24-1.00=0.24)$ when moving from employed individual to unemployed individual. This means that there will be $76 \%$ increase in the likelihood of being insured for every one unit increase in the number of employed people in Nigeria. 
The model summary table is displayed in Table 9. The Nagelkerke R-square indicates that $16.3 \%$ of the total variations in insurance cover are present due to the variations among the three predictor variables.

Table-9. Model Summary.

\begin{tabular}{c|c|c|c}
\hline Step & -2 Log likelihood & Cox \& Snell R Square & Nagelkerke R Square \\
\hline 1 & $23266.995^{\mathrm{a}}$ & 0.033 & 0.163 \\
\hline
\end{tabular}

Further, graphs of predicted probabilities are used to understand and/or present the model. Therefore, the plot with the predicted probabilities is presented in Figure 2. Recall that 1 represents Higher Education, 2 represents Secondary Education, 3 represents Primary Education and 4 represents No Formal Education in the levels of education as displayed. The plot in Figure 2 shows that the model predicted probabilities for insurance cover increases significantly with age for only those that are with higher education, followed by those with secondary school education while it remained almost the same for those with primary education or no formal education at all.

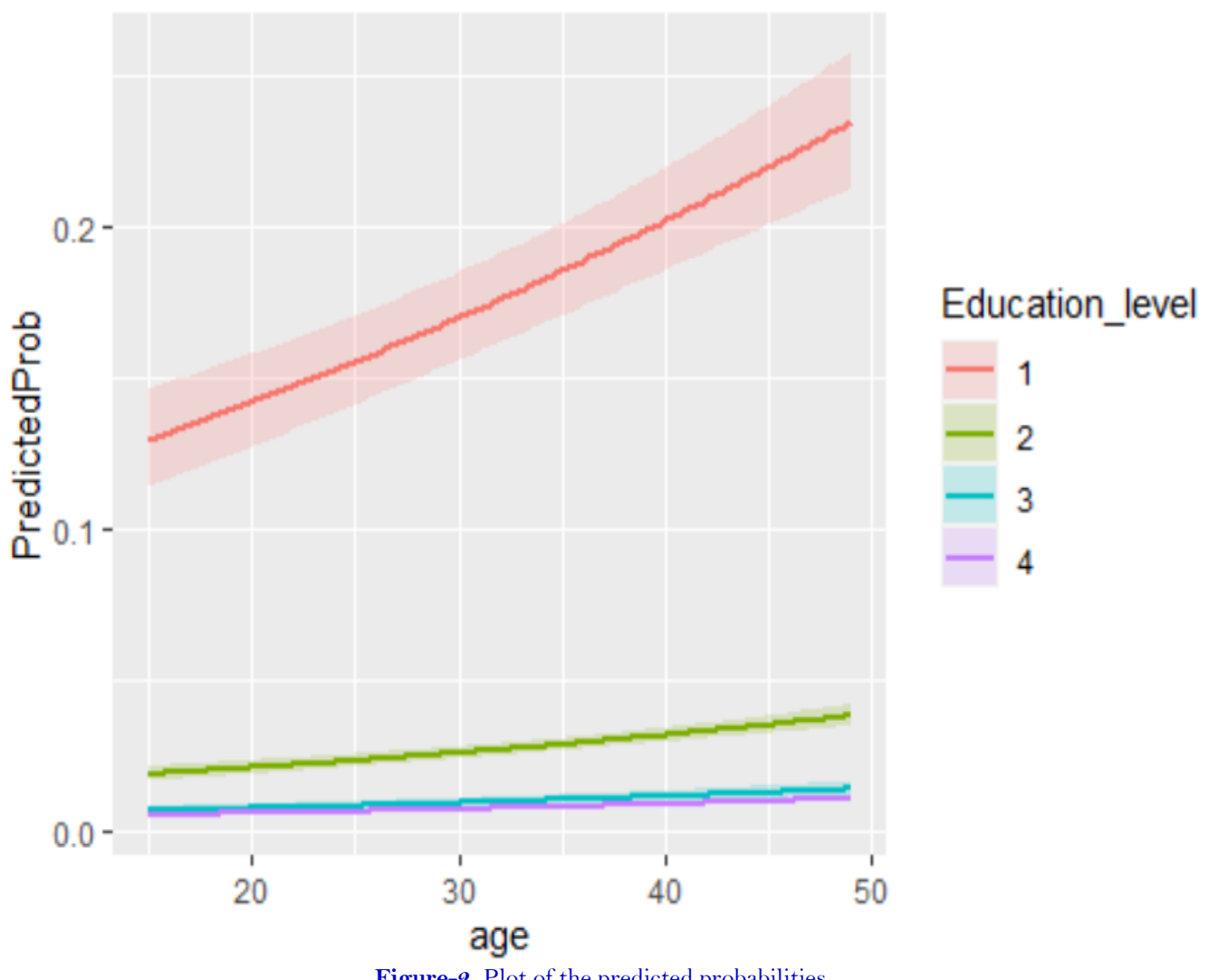

\section{SUMMARY, CONCLUSION AND RECOMMENDATION}

This section discusses the summary of the findings of this work, the conclusion based on the findings and recommendations.

\subsection{Summary}

The binary logistic regression model was used to model the described dataset; the model so obtained was statistically significant. All the levels of education were statistically significant in predicting the odds of having insurance cover except for primary education level. This may be because primary education level is not enough for the individual to fully understand the dividends of insurance cover. Also, employment status and age were statistically significant in predicting the likelihood for insurance cover in Nigeria. Based on the findings of results of this work in section 3 , the answers to our research objectives follow: 
Table-10. Summary of findings.

\begin{tabular}{l|l|l}
\hline Variable & Relative Risk (p-value) & Interpretation \\
\hline Higher Education & 21.66 (significant at 5\%) & $\begin{array}{l}\text { This means that individuals who move from no } \\
\text { formal education to obtain Higher education level } \\
\text { are } 21.66 \text { times more likely to obtain an insurance } \\
\text { cover. }\end{array}$ \\
\hline Secondary Education & $2.63($ significant at 5\%) & $\begin{array}{l}\text { This means that individuals who move from no } \\
\text { formal education to obtain Secondary education } \\
\text { level are 2.63 times more likely to obtain an } \\
\text { insurance cover. }\end{array}$ \\
\hline Primary School & 1.03 (not significant at $5 \%)$ & $\begin{array}{l}\text { The odd ratio is not significant and therefore } \\
\text { should not be interpreted. }\end{array}$ \\
\hline Employment Status & $1.24($ significant at 5\%) & $\begin{array}{l}\text { This means that individuals who move from being } \\
\text { unemployed to being employed are } 76 \% \text { that is } 1- \\
(1.24-1.00=0.24)=76 \% \text { more likely to obtain } \\
\text { an insurance cover. The subtraction from } 1 \text { is } \\
\text { fecause the reference level was unemployed } \\
\text { status. }\end{array}$ \\
\hline Respondent's Age & 2.1 (significant at 5\%) & $\begin{array}{l}\text { This means that increasing age increases the odds } \\
\text { of obtaining of obtaining insurance cover by } 2.1 .\end{array}$ \\
\hline
\end{tabular}

Finally, $16.3 \%$ of the total variations in the classification of whether or not an individual has an insurance cover in Nigeria occurred due to the variations among the three predictor variables (education level, employment status and age), see Table 9.

\subsection{Conclusion}

Table 10 has revealed that the likelihood of obtaining insurance cover increases for those at the upper end of the education distribution. This particular finding is not in agreement with the findings of Beck and Webb (2003) but in agreement with two studies in the preceding year (Burnett \& Palmer, 2004; Hammond et al., 2007; Truett \& Truett, 2004). It is also observed that employment status and age of the individual contributes to the purchase of insurance in Nigeria. However, educational level has the highest impact (odds $=21.66$ ), followed by age (odds $=2.1$ ) and then employment status (odds $=0.76)$.

\subsection{Recommendation}

It has been revealed by this study that there is need to put more efforts in inclusive and equitable quality education which is one of the major 2030 agenda for Sustainable Development Goals (SDG). This particular SDG will help promote lifelong opportunities for all, ensure that all learners acquire the knowledge and skills to promote sustainable development and increase the likelihood for insurance cover so that individuals who lose their loved ones or their lives through terror and insecurity situation in Nigeria have something to beckon. There is also need to bring insurance sensitization to the younger age distribution and provide employment opportunities to the teaming population of youths in Nigeria.

Funding: This study received no specific financial support.

Competing Interests: The authors declare that they have no competing interests.

Acknowledgement: All authors contributed equally to the conception and design of the study.

\section{REFERENCES}

Beck, T., \& Webb, I. (2003). Economic, demographic, and institutional determinants of life insurance consumption across countries. The World Bank Economic Review, 17(1), 51-88. Available at: https://doi.org/10.1093/wber/lhgo1 1.

Burnett, J. R., \& Palmer, A. (2004). Examining life insurance ownership through demographic and psychographic characteristics. Journal of Risk and Insurance, 51(3), 453-467. Available at: https://doi.org/10.2307/252479. 
Buzatu, C. (2013). The influence of behavioral factors on insurance decision-A Romanian approach. Procedia Economics and Finance, 6, 31-40. Available at: https://doi.org/10.1016/s2212-5671(13)00110-x.

Ebiede, T. M. (2021). How insecurity affects the lives of everyone in the Niger Delta. The conversation. Retrieved from https://theconversation.com/how-insecurity-affects-the-lives-of-everyone-in-the-niger-delta-158182.

Haeil, A. (2014). Effect modeling of count data using logistic regression with qualitative predictors. Engineering, 6(12), 758-772. Available at: https://doi.org/10.4236/eng.2014.612074.

Hammond, J. D., Houston, D. B., \& Melander, E. R. (2007). Determinants of household life insurance premium expenditures: An empirical investigation. Journal of Risk and Insurance, 34(3), 397-408. Available at: https://doi.org/10.2307/250854.

Nkengmenche, G. N. (2020). Factors affecting the successful uptake of life insurance in Cameroon: Zenithe Insurance Company, Buea, Cameroon, Centria University of Applied Sciences. Retrieved from: https://www.theseus.fi/bitstream/handle/10024/337180/Njukang\%20Golden.pdf? sequence=2\&isAllowed=y.

[Accessed 22/09/2021].

Park, S., \& Lemaire, J. (2012). The impact of culture on the demand for non-life insurance. ASTIN Bulletin: The Journal of the IAA, $42(2), 501-527$.

Ramos, J. C., Lieberman-Cribbin, W., Gillezeau, C., Alpert, N., Gerven, M. V., Tuminello, S., \& Taioli, E. (2019). Medical bankruptcy: Still common despite the affordable care act. AJPH, 109(3), 431-433. Available at: https://doi.org/10.2105/ajph.2018.304901.

Salami, K. A. (1996). Development of life business-role of the African life reinsurance. Paper presented at the African Insurance Organization (AIO) Seminar of Life Assurance, Mombasa Kenya, November 27-28.

Truett, \& Truett. (2004). Risk and insurance in village India. Econometrica, 62(3), 539-592. Available at: https://doi.org/10.2307/2951659.

Ugwuanyim, G., Onwuegbuchunam, D., Bartholomew, D., \& Anikpe, C. (2021). Performance evaluation of motor insurance companies: Panel data evidence from Nigeria. Journal of Transportation Technologies, $11(3)$, 325-334. Available at: https://doi.org/10.4236/jtts.2021.113021.

Yildirim, I., \& Cakar, R. (2015). A study of the factors affecting the insurance company preferences of insurance agencies in Turkey. International Journal of Business and Management Studies, 7(1), 1-15. 